SHORT REPORT

\title{
Family support for stroke: one year follow up of a randomised controlled trial
}

\author{
J Mant, S Winner, J Roche, D T Wade
}

J Neurol Neurosurg Psychiatry 2005;76:1006-1008. doi: 10.1136/jnnp.2004.048991

\begin{abstract}
Background: There is evidence that family support can benefit carers of stroke patients, but not the patients themselves.

Objective: To extend the follow up of a single blind randomised controlled trial of family support for stroke patients and carers to one year to ascertain whether there were any late effects of the intervention.

Methods: The study was a randomised controlled trial. Patients admitted to hospital with acute stroke who had a close carer were assigned to receive family support or normal care. Families were visited at home by a researcher 12 months after the stroke, and a series of questionnaires was administered to patient and carer.

Results: The benefits to carers mostly persisted, though they were no longer statistically significant because some patients were lost to follow up. There was no evidence of any effects on patients.

Conclusion: Family support is effective for carers, but different approaches need to be considered to alleviate the psychosocial problems of stroke patients.
\end{abstract}

! recognition of the impact that stroke has on carers as well as patients, ${ }^{1}$ services such as Stroke Association family support have been developed in the United Kingdom which provide information, emotional support, and liaison with other services. The service maintains contact through a combination of home and hospital visits and telephone calls. In the Oxford family support trial, we found that this service was associated with significantly improved quality of life of carers at follow up six months after the stroke, but had no effects on patients. ${ }^{2}$ Other randomised controlled trials of the service in other areas have also found no evidence of benefit to patients with follow up varying from four to nine months after recruitment. ${ }^{3}{ }^{4}$ The lack of benefit to patients may be attributable to the short duration of follow up in these trials. The service usually maintains contact with a family for a year, and some patients spend a significant proportion of the first six months in hospital, during which time family support might be anticipated to have less impact. We carried out a second follow up of participants in the Oxford trial to investigate the effects of family support on patients and carers one year after the stroke.

\section{METHODS}

The methods and principal results of the Oxford family support study have been reported elsewhere. ${ }^{2}$ In brief, patients admitted to hospital with acute stroke who had a close family carer were randomly allocated to receive normal care (controls) or normal care plus contact with a stroke family support organiser (FSO). The level of contact with each family was at the discretion of the FSO. For the one year follow up (as at six months), the families were visited at home by a researcher who was blinded to intervention group status. The measures used are shown in table 1 . The 12 month follow up was carried out before the results of the six month follow up were known. If carers were not present, questionnaires were left for self completion and return by post.

We had estimated that 300 participants would be needed to detect clinically relevant differences between groups with $80 \%$ power. Data were analysed using SPSS for windows (version 10.0). The significance of differences between FSO and control groups was assessed with the Mann-Whitney test. To explore the characteristics of carers who dropped out between six and 12 months, six month outcomes where there had been significant differences between intervention and control-the Frenchay activities index, quality of life using the Dartmouth Coop chart, and five dimensions of the SF-36 (energy, mental health, pain, physical function, and general health perception)—were compared in carers who did and did not participate at 12 months. Ethics approval was granted by the Central Oxford research ethics committee.

\section{RESULTS}

Of 520 randomised patients, 388 (75\%) were still alive at 12 months. Consent was obtained after randomisation, and 50 families declined involvement, ${ }^{2}$ leaving 338 potential participants at 12 months, of whom 296 (90\% of intervention group and $86 \%$ of control group) were followed up (fig 1). Seventy four per cent of carers in the intervention group and 69\% in the control group were followed up. In three cases (all in the intervention group), the carer had died but in the remainder the carer was not available when the patient was interviewed and did not return the questionnaires left for self completion.

Between six and 12 months, the FSO visited 65 families at home $(44 \%)$, contacted $120(81 \%)$ by telephone at least once, and liaised with other services for 15 families (10\%). She visited only four patients in hospital. Twenty seven families (18\%) had no contact with the FSO after six months. The average number of contacts of any sort between six and 12 months was three (as compared with five in the first six months). Patients in the intervention group who were followed up had significantly more contact with the FSO, with a mean total number of contacts of $7.8(n=148)$ over the twelve months, as compared to $5.1(n=45)$ contacts in those not followed up $(\mathrm{p}<0.001)$.

Carer outcomes (table 1) were similar to those obtained at six month follow $u^{2}$ in that all but two of the differences were in favour of the intervention, and of the same order of magnitude with two exceptions. For both the Frenchay activities index and the mental health component of the SF36 , the differences observed at 12 months was smaller than those seen at six months. Patient outcomes (table 1) were

Abbreviations: FSO, family support organiser; SF-36, short form 36 item health assessment questionnaire 
Table 1 Carer and patient outcomes one year after stroke

\begin{tabular}{|c|c|c|c|c|c|c|c|}
\hline \multirow[b]{2}{*}{ Outcome measures } & \multicolumn{2}{|l|}{ Median (IQR) scores } & \multirow{2}{*}{$\begin{array}{l}\text { Difference } \\
\text { between } \\
\text { scores* }\end{array}$} & \multirow{2}{*}{$\begin{array}{l}\text { Range of scale } \\
\text { (bad-good) }\end{array}$} & \multicolumn{2}{|c|}{$\begin{array}{l}\text { Number of } \\
\text { complete responses }\end{array}$} & \multirow[b]{2}{*}{$p$ Value } \\
\hline & FS & C & & & FS & C & \\
\hline \multicolumn{8}{|l|}{ Carers } \\
\hline Frenchay activities index & 32 (28 to 35$)$ & 32 (28 to 36$)$ & 0.0 & 0 to 45 & 103 & 96 & 0.97 \\
\hline GHQ-28 & $17(10$ to 24$)$ & 17 (13 to 23$)$ & +0.3 & 84 to 0 & 93 & 90 & 0.38 \\
\hline $\begin{array}{l}\text { Caregiver strain index } \\
\text { SF-36 }\end{array}$ & $4(1$ to 6$)$ & $3(1$ to 6$)$ & -0.3 & $\begin{array}{l}13 \text { to } 0 \\
0 \text { to } 100\end{array}$ & 107 & 100 & 0.37 \\
\hline Change in health & $50(25$ to 50$)$ & 50 (25 to 50$)$ & -3.2 & & 106 & 101 & 0.18 \\
\hline Energy and vitality & 55 (35 to 70$)$ & $55(35$ to 60$)$ & +5.2 & & 103 & 93 & 0.05 \\
\hline Mental health & $76(64$ to 88$)$ & $72(60$ to 84$)$ & +1.7 & & 101 & 95 & 0.25 \\
\hline Pain & $88.9(55.6$ to 100$)$ & $72.2(55.6$ to 100$)$ & +5.7 & & 108 & 98 & 0.08 \\
\hline Physical function & $90(70$ to 100$)$ & $80(65$ to 95$)$ & +4.9 & & 103 & 94 & 0.08 \\
\hline Role limitation (emotional) & $100(100$ to 100$)$ & $100(66.7$ to 100$)$ & +1.9 & & 106 & 95 & 0.65 \\
\hline Role limitation (physical) & $100(75$ to 100$)$ & $100(50$ to 100$)$ & +7.8 & & 106 & 95 & 0.23 \\
\hline Social function & $100(88.9$ to 100$)$ & $100(77.8$ to 100$)$ & +3.2 & & 98 & 87 & 0.51 \\
\hline General health perception & 82 (61.5 to 87$)$ & 72 (54.2 to 87$)$ & +5.3 & & 105 & 93 & 0.07 \\
\hline Dartmouth co-op chart & & & & 5 to 1 & & & \\
\hline Physical fitness & $3(2$ to 4$)$ & $3(2$ to 4$)$ & +0.2 & & 91 & 83 & 0.38 \\
\hline Feelings & $2(1$ to 3$)$ & $2(1$ to 3$)$ & +0.2 & & 90 & 81 & 0.19 \\
\hline Daily activities & $1(1$ to 2$)$ & 1 (1 to 3 ) & +0.3 & & 91 & 82 & 0.06 \\
\hline Social activities & $1(1$ to 1$)$ & $1(1$ to 2$)$ & +0.2 & & 89 & 83 & 0.14 \\
\hline Pain & $3(1$ to 4$)$ & $3(1$ to 4$)$ & +0.2 & & 89 & 83 & 0.36 \\
\hline Change in health & $3(3$ to 3$)$ & 3 (3 to 3$)$ & +0.2 & & 92 & 81 & 0.09 \\
\hline Overall health & $3(2$ to 3$)$ & $3(2$ to 4$)$ & +0.1 & & 92 & 83 & 0.54 \\
\hline Social support & 1 (1 to 3$)$ & 1 (1 to 3$)$ & +0.2 & & 91 & 84 & 0.48 \\
\hline Quality of life & $2(2$ to 3$)$ & $2(2$ to 3$)$ & +0.2 & & 90 & 82 & 0.19 \\
\hline \multicolumn{8}{|l|}{ Patients } \\
\hline Barthel index & $17(13$ to 19$)$ & 18 (15 to 20$)$ & -1.0 & 0 to 20 & 146 & 148 & 0.06 \\
\hline Rivermead mobility index & $9(4$ to 13.75$)$ & 11 (7 to 13$)$ & -1.0 & & 144 & 146 & 0.17 \\
\hline Frenchay activities index & $13.5(6$ to 28$)$ & $15.5(6$ to 25$)$ & +0.2 & & 142 & 138 & 0.92 \\
\hline London handicap scale & 63.4 (54.6 to 75.3$)$ & $63.4(55.1$ to 74.1$)$ & +0.5 & & 135 & 144 & 0.98 \\
\hline HADS & & & & 21 to 0 & & & \\
\hline Anxiety & $4(2$ to 7$)$ & $4(2$ to 7$)$ & -0.3 & & 119 & 118 & 0.58 \\
\hline Depression & $5(3$ to 7$)$ & $5(3$ to 7$)$ & -0.2 & & 115 & 109 & 0.51 \\
\hline \multicolumn{8}{|l|}{ Dartmouth co-op chart } \\
\hline Physical fitness & $5(4$ to 5$)$ & $5(4$ to 5$)$ & 0 & 5 to 1 & 145 & 146 & 0.92 \\
\hline Feelings & 2 (1 to 3 ) & 2 (1 to 3$)$ & -0.1 & & 142 & 145 & 0.32 \\
\hline Daily activities & $3(2$ to 4$)$ & $3(2$ to 4$)$ & 0 & & 143 & 146 & 0.88 \\
\hline Social activities & $2.5(1$ to 4$)$ & $3(1$ to 4$)$ & +0.1 & & 142 & 145 & 0.48 \\
\hline Pain & $3(1$ to 4$)$ & $3(1$ to 4$)$ & -0.2 & & 145 & 145 & 0.36 \\
\hline Change in health & 3 (3 to 3$)$ & 3 (3 to 3 ) & 0 & & 141 & 146 & 0.79 \\
\hline Overall health & $3(3$ to 4$)$ & $3(3$ to 4$)$ & +0.1 & & 141 & 146 & 0.59 \\
\hline Social support & $1(1$ to 1$)$ & $1(1$ to 2$)$ & +0.1 & & 140 & 147 & 0.33 \\
\hline Quality of life & $2(2$ to 3$)$ & $2(1$ to 3$)$ & 0 & & 139 & 146 & 0.47 \\
\hline
\end{tabular}

*Difference between mean family support and mean control scores; positive difference in means always favours intervention.

C, control; FS, family support; GHQ-28, 28 item version of the general health questionnaire; HADS, hospital anxiety and depression scale; IQR, interquartile range; SF-36, 36 item short form health assessment questionnaire.

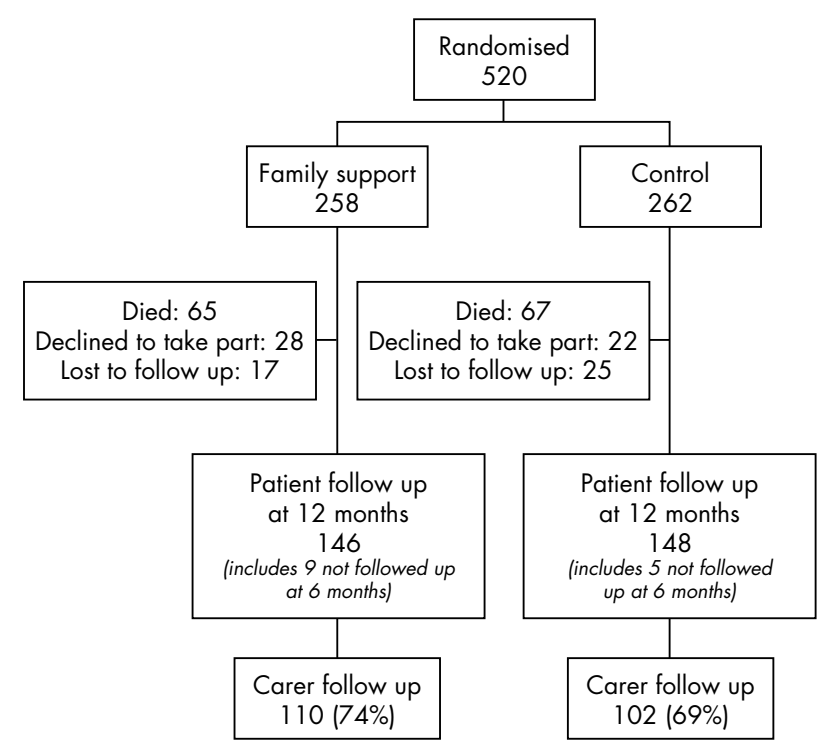

Figure 1 Patient flows through the study. also similar to those obtained at the six month follow up: some differences favoured the FSO group and some the control group. None of the differences was statistically significant.

For six of the seven measures tested, carers who were followed up at both six and 12 months had better mean outcomes at six months than carers who were only followed up at six months. For one of these measures (SF-36 general health perception), the difference was statistically significant $(72.2 \vee 63.6, \mathrm{p}=0.02)$.

\section{DISCUSSION}

We found no evidence of benefit to stroke patients from a family support service at one year. In contrast to our earlier report, ${ }^{2}$ we also found no significant benefits to carers at one year. Nevertheless, the 12 month carer outcomes were broadly similar to the six month outcomes. Fifty five fewer carers were followed up at 12 months than at six months, so the likeliest explanation for the non-significant results for carers at 12 months is loss of statistical power. This will have been exacerbated by differential loss to follow up of carers with worse outcomes at six months. In contrast, adequate power was maintained to detect any important differences affecting patients at one year. Within the intervention group, 
patients with greater contact with the FSO were more likely to be followed up. The impact of this on the results is difficult to predict. On the one hand, families with more contact with the FSO tended to have worse outcomes, ${ }^{2}$ but on the other hand, they will have been more likely to have derived benefit. The negative result of this study is consistent with another trial of a related intervention-specialist nurse supportwhich followed up stroke patients for one year. ${ }^{5}$ While family support is effective for carers, different approaches such as formal training of carers ${ }^{6}$ need to be considered to address the psychosocial problems of stroke patients.

\section{Authors' affiliations}

J Mant, Department of Primary Care and General Practice, University of Birmingham, Birmingham, UK

S Winner, Department of Clinical Geratology, Raddliffe Infirmary, Oxford, UK

J Roche, School of Health and Social Care, Oxford Brookes University, Oxford

D T Wade, Neurological Rehabilitation Service, Oxford Centre for Enablement, Windmill Road, Oxford

The study was funded by the Stroke Association. All the authors are fully independent from the Stroke Association.
Competing interests: Both DTW and JM have received research grants from the Stroke Association and have in the past served on the Research and Development Committee of the Stroke Association.

Correspondence to: Dr Jonathan Mant, Department of Primary Care and General Practice, Primary Care Clinical Sciences Building, University of Birmingham, Birmingham B15 2TT, UK; j.w.mant@bham. ac.uk

Received 1 July 2004

In revised form 10 September 2004

Accepted 29 October 2004

\section{REFERENCES}

1 Han B, Haley WE. Family caregiving for patients with stroke: review and analysis. Stroke 1999;30:1478-85.

2 Mant J, Carter J, Wade DT, et al. Family support for stroke: a randomised controlled trial. Lancet 2000;356:808-13.

3 Dennis M, O'Rourke S, Slattery J, et al. Evaluation of a stroke family care worker: results of a randomised controlled trial. BMJ 1997;314:1071-7.

4 Lincoln NB, Francis VM, Lilley SA, et al. Evaluation of a stroke family support organiser. Stroke 2003;34:116-21.

5 Forster A, Young J. Specialist nurse support for patients with stroke in the community: a randomised controlled trial. BMJ 1996;312:1642-6.

6 Kalra L, Evans A, Perez I, et al. Training carers of stroke patients: randomised controlled trial. BMJ 2004;328:1099-101. 